Original Research Paper

\title{
Activity Index and Author Exponential Growth on Forensic Medicine
}

\author{
C. Baskaran and P. Ramesh Babu \\ Department of Library and Information Science, Alagappa University, Karaikudi-630 003, India
}

\author{
Article history \\ Received: 24-04-2018 \\ Revised: 06-09-2018 \\ Accepted: 20-10-2018 \\ Corresponding Author: \\ C. Baskaran \\ Department of Library and \\ Information Science, Alagappa \\ University, Karaikudi-630 003, \\ India \\ Email: cbklis@gmail.com
}

\begin{abstract}
The study examines the activity index and exponential growth of authors analysed during 1989-2016. The result of the study found that publications growth between $11(0.26 \%)$ in 1989 and $447(10.76 \%)$ in 201 . RGR shows a fluctuates trend between 0.02 and 1.02 in 2005, 2006 and 1991 respectively. Complete twenty three years the research could be observed that RGR less than 1. DC between 0.64 and 0.94 . Further, overall DC measured 23.08 throughout study period. It witnessed CI values measured between 0.04 and 5.56 in the year 2014 and 2009 respectively. The CC values measured between 9.87 in 2016 and 6.15 in 1995 and 1995 , the whole CC observed as 230.26 over period of study.
\end{abstract}

Keywords: Forensic Medicine, Relative Growth Rate (RGR), Doubling time (Dt), Degree of Collaboration (DC), Collaborative Co-efficient (CC), Collaborative Index (CI)

\section{Introduction}

Forensic Medicine today is a large medical field that includes many sub areas. However, generally, when one speaks or thinks about it, one associates it immediately with death, autopsies and related problems (Kaye, 1992). Yet, this is only part of legal medicine, as new approaches and sub specialties are realized because of the advances in medical sciences and socio-political changes around the world. Forensic anthropology and clinical Forensic Medicine are perhaps the best examples of these "New Sciences."

The origin of Forensic Medicine remains lost in a distant past, whenever the principles of medical sciences met those of law and justice (Kovacevic, 1998). Perhaps it began with the Code of Hammurabi (1792-1750 BCE), which imposed sanctions for errors in medical and surgical practices. The same type of punishment also existed in Persia.

Forensic dissections of bodies began in the 13th century at the University of Bologna in Italy by a surgeon and teacher of anatomy, Saliceto (Saukko and Knight, 2004). Surprisingly, these forensic dissections appeared before the hospital autopsies that started by the end of the $19^{\text {th }}$ century with Rokitansky, Virchow and the advent of the pathogenesis of diseases and cellular pathology.

However, some authors consider the French surgeon AmbrosioParé, who in 1575 began a real scientific period in rance, the father of legal medicine. This paternity is divided with Zacchia, the Pope's physician, who taught in Italy and wrote in 1601 what can be considered the first medicolegal textbook.

Measuring and analysing science, technology and innovation. Major research issues include the measurement of impact, reference sets of articles to investigate the impact of journals and institutes, understanding of scientific citations, mapping scientific fields and the production of indicators for use in policy and management contexts. In practice there is a significant overlap between Scientometrics and other scientific fields such as Bibliometrics, information systems, information science and science of science policy.

\section{Review of Literature}

Sevinc $(2004 ;$ 2005) It was demonstrated that scientometrics, which includes use of mathematical techniques to investigate publishing and communication patterns in the distribution of information, has been an established approach in occupational and industrial health for about 20 years (Smith, 2007). Scientometrics is defined as the measurement and analysis of science, often using bibliometrics, the measurement scientific publications. Modern scientometrics are based on (de Solla Price, 1977) and Garfield (2007). Despite growing interest and research output in this field, the scientific data that has been published to date on ETS has 
not been dissected in detail by means of scientometrics. By contrast, the existing scientometric studies have had a more general focus (de Granda-Orive et al., 2007; 2009; Vitzthum et al., 2010). A combination of scientometric methods and novel visualizing procedures were used, including density-equalizing mapping and radar charting techniques. 6,580 ETS-related studies published between 1900 and 2008 were identified in the ISI database. Using different scientometric approaches, a continuous increase of both quantitative and qualitative parameters was found. Jeyasekar and Saravanan (2013) carried out a bibliometric study of the Journal of Forensic Sciences and found that there is an increase in pub lications on digital and multimedia aspects of forensic science and the literature related to application of DNA technology in forensic science is also increasing. The mean degree of authorship collaboration is 0.91 . The latter also founded the Institute for Scientific Information with the database Web of Science. Baskaran (2015), examined the confront the publications output trend among USA scientists, Wang Y has secured top level as measured $0.226 \%$. USA scientists have contributed totally 15832 (30.815\%) items and include $87.947 \%$ are appeared as journal articles. Harvard University scientists are much attention in produced large number of research papers and they hold top level among research collaboration in enzyme research. Kolle and Shankarappa (2016), examined the coverage of Indian medical literature in MEDLINE was not comprehensive and this affects visibility of Indian medical research output. So Indian Council of Medical Research (ICMR) launched IndMed and MedInd. There are no studies investigating the coverage, the services and the gaps in coverage of IndMed. Subramanyam and Krishnamurthy (2017), discussed the growth of research work in the field of social sciences and humanities in Odisha during the period 1996 to 2015. The analysis has been done taking into account the publication output of Odisha as reflected in Scopus database. Sivakami and Baskaran (2016), examined the Swine Flu is that, unlike seasonal flu, which is typically most dangerous to the very young, elderly and those with a weakened immune system. By keeping this in mind the researcher intends to study the research productivity of Swine Flu. This study attempts to analyze the performance of researcher working in the field of swine flu at global level and country wise distribution during the study period of 23 years from 1991 to 2013. Baskaran (2016), explored the relative growth rate and doubling time of Bioinformatics Publication during 1999-2013. The mean relative growth was measures and doubling time observed from the analysis. Total number 20577 of records on bioinformatics publication during the study. The
Maximum of Publications 2234 in 2012 was published compare to rest of the years. Ramesh Babu and Baskaran (2017), analyzed the highest out of Forensic Medicine research Forensic Medicine research in 2013 was $447(11.05 \%)$ of the publications, followed by 420 $(10.38 \%)$ of the publication brought out in 2015 . the doubling time of the publications also a fluctuate trend appears whole study period. It could be found that the highest Dt. is 17.32 in 1993. The Journal of Solar Energy Engineering, Transactions of the ASME has published 2361 articles during the period of 1980-2016 with an yearly average of 63.81 . The maximum number of articles $114(4.83 \%)$ were published in the year of 2015. In the Authorship Pattern, the major contribution of articles was from two authors 776 (32.87\%) (Radhakrishnan and Baskaran, 2018). 1 "Economic Affairs" and the Relationship of measuring and analyzing the Articles, Authorship, Type of document, Growth Ratio, Relative Growth Rate etc.. This paper critically analyses 2313 scholarly communications published in the Economic Affairs Journal. The analysis cover mainly the number of articles, form of document, the study is obtained from the SCOPUS database in 2313 results for thirty seven years in this results retrieved are analyzed using excel worksheets (Palanivel and Baskaran, 2018).

\section{Objectives of the Study}

1. To know the year-wise distribution of research output from Web of Science (WOS) PubMed database in Forensic Medicine

2. To examine the Relative Growth Rate (RGR) and Doubling time (Dt) of the publications in Forensic Medicine from Web of Science (WOS) database

3. To analyze the Degree of Collaboration and Measuring of Collaboration of the authors

4. To analyze the Exponential Growth for authors and Activity Index on brought out the research Literature in Forensic Medicine

\section{Significance of the Study}

The study analysed the publications brought out by the researchers in the field of Forensic Medicine during 1989-2016. The study leads to identify the people, including the specialists working on Forensic Medicine area, which have to be discussed difficulties in distinguishing among cause, manner and mechanism of death. Cause of death means any injury or disease that generates a pathological alteration in the body that leads to the individual's death. It is possible that a mechanism of death is shared by different causes of death may result from blunt trauma, stabbing, or lung carcinoma. In order to the study has taken by the researcher entitled "ACTIVITY 
INDEX AND AUTHOR EXPONENTIAL GROWTH ON FORENSIC MEDICINE."

\section{Limitations of the Study}

The data of Web of Science (WOS) database and PubMed databases in Forensic Medicine during 19892016. The data retrieved in search terms of "Forensic Medicine" could have been extracted the data during the study. The study rely on the research publications of Forensic Medicine, due to researcher's convenient and it has been computed the complete bibliographical details in respective of Growth of Literature, Author Productivity, father analysis made on RGR and Doubling time of publications, Activity Index, Exponential Growth of authors etc.

\section{Methodology}

The study analyzed the impact of the publications in Forensic Medicine research at the global prospective. The study explores the research contribution of the countries growth and their trends have been investigated during 1989-2016. The present study attempts to extract the data of Web of Science (WOS) database. Totally 4152 records were retrieved from Web of Science (WOS) database during the period of study. The publications have been extracted the Web of Science (WOS) data on Forensic Medicine was covered during 1989-2016. Data exported in Excel sheets according to various parameters needed for study. Then all the indicators quality, quantity consistency for countries, institution, authors, journal etc. were exported on excel sheets. Moreover, the study find being taken analysis about RGR and Doubling time of publications, Degree of Collaboration of authors, Collaborative Index, Collaborative Co-efficient, Modified Collaborative Co-efficient, Activity Index and Exponential Growth of authors.

\section{Data Analysis}

Year-Wise Distribution of the Publications on Forensic Medicine (WOS)

It has been analyzed the research growth in the field of Forensic Medicine and these records retrieved from Web of Science (WOS) database during 1989 2016. The result found that publications growth between $11(0.26 \%)$ in 1989 and $447(10.76 \%)$ in 201 . Table 1 observed that largest output was found 447 publications in the year 2013 and it followed by 420 $(10.38 \%)$ of the publications were identified in 2015 . There were no record published in the year 2003. Further, It could be found that overall publications growth to be appeared as a fluctuated trend in the year 1992, 1997, 2002, 2011 and 2014 (Fig. 1).
Table 1: Year-wise distribution of the publications on forensic medicine (WOS)

\begin{tabular}{lcrc}
\hline Year & No. of output & \% & Cumulative \% \\
\hline 1989 & 11 & 0.26 & 0.26 \\
1990 & 17 & 0.40 & 0.66 \\
1991 & 47 & 1.13 & 2.82 \\
1992 & 43 & 1.02 & 3.90 \\
1993 & 45 & 1.08 & 4.98 \\
1994 & 45 & 1.08 & 6.23 \\
1995 & 52 & 1.25 & 7.69 \\
1996 & 61 & 1.45 & 8.94 \\
1997 & 52 & 1.25 & 10.61 \\
1998 & 69 & 1.66 & 12.18 \\
1999 & 66 & 1.58 & 13.84 \\
2000 & 69 & 1.66 & 15.98 \\
2001 & 89 & 2.14 & 18.00 \\
2002 & 84 & 2.02 & 18.00 \\
2003 & 0 & 0.00 & 0.00 \\
2004 & 82 & 1.97 & 19.97 \\
2005 & 100 & 2.40 & 22.37 \\
2006 & 101 & 2.42 & 24.79 \\
2007 & 143 & 3.44 & 28.23 \\
2008 & 148 & 3.56 & 31.79 \\
2009 & 277 & 6.67 & 38.46 \\
2010 & 308 & 7.41 & 45.87 \\
2011 & 287 & 6.91 & 52.78 \\
2012 & 294 & 7.08 & 59.86 \\
2013 & 447 & 10.76 & 70.62 \\
2014 & 365 & 8.79 & 79.41 \\
2015 & 420 & 10.11 & 89.65 \\
2016 & 430 & 10.35 & 100.00 \\
Total & 4152 & 100.00 & \\
\hline & & &
\end{tabular}

Relative Growth Rate (RGR) and Doubling time (Dt) of the Publications (WOS)

Relative Growth Rate (RGR) and Doubling time (Dt) of the publications in Forensic Medicine records retrieved from Web of Science. It has analyzed Table 2 the RGR shows a fluctuates trend between 0.02 and 1.02 in 2005, 2006 and 1991 respectively. Complete twenty three years the research could be observed that RGR less than 1. Similarly, Fig. 2 indicates the Doubling Time of the publications also seems that a fluctuated trend throughout the study period and there was observed the highest Dt was 34.65 in the year 2016.

However, it could be analyzed from the discussion; RGR range was measured between 0.02 and 1.02 in the year 2016 and 1991 respectively, on the other hand, Dt range was found between 1.1 and 34.65 in the year 2009 and 2016 respectively indicated in Fig. 2.

\section{Degree of Collaboration of Authors}

Table 3 observed that Degree of collaboration was measured in different years as per the Subramanian formulae and it reflects that degree of collaboration of the authors for over twenty eight years between 1989 and 2016. Normally where we can find the more quantum of 
papers appeared on Multi authors rather than single authors. It can be found DC between 0.64 and 0.94 . Further, overall DC measured 23.08 throughout study period. Finally, the results of the DC were an increased and a decreased trend appeared in the whole study period exhibited in Fig. 3.

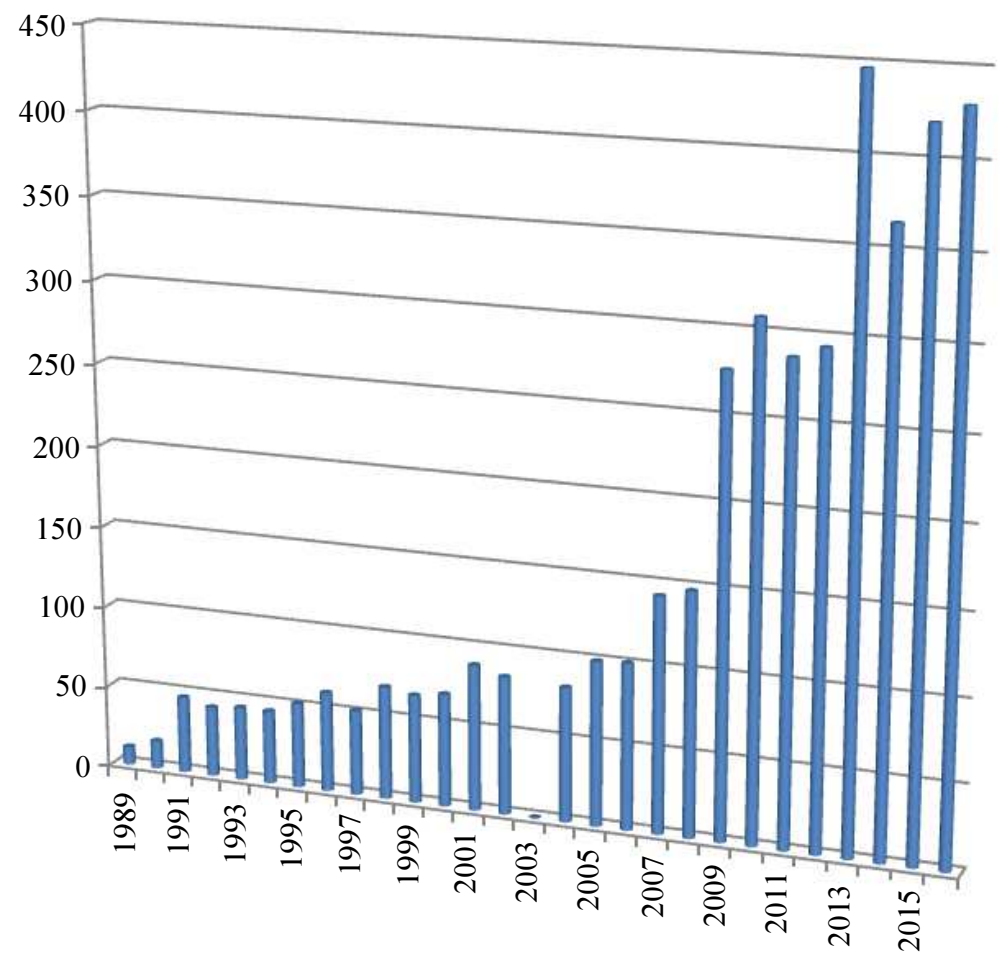

Fig. 1: Year-wise distribution of the Publication on Forensic Medicine (WOS)

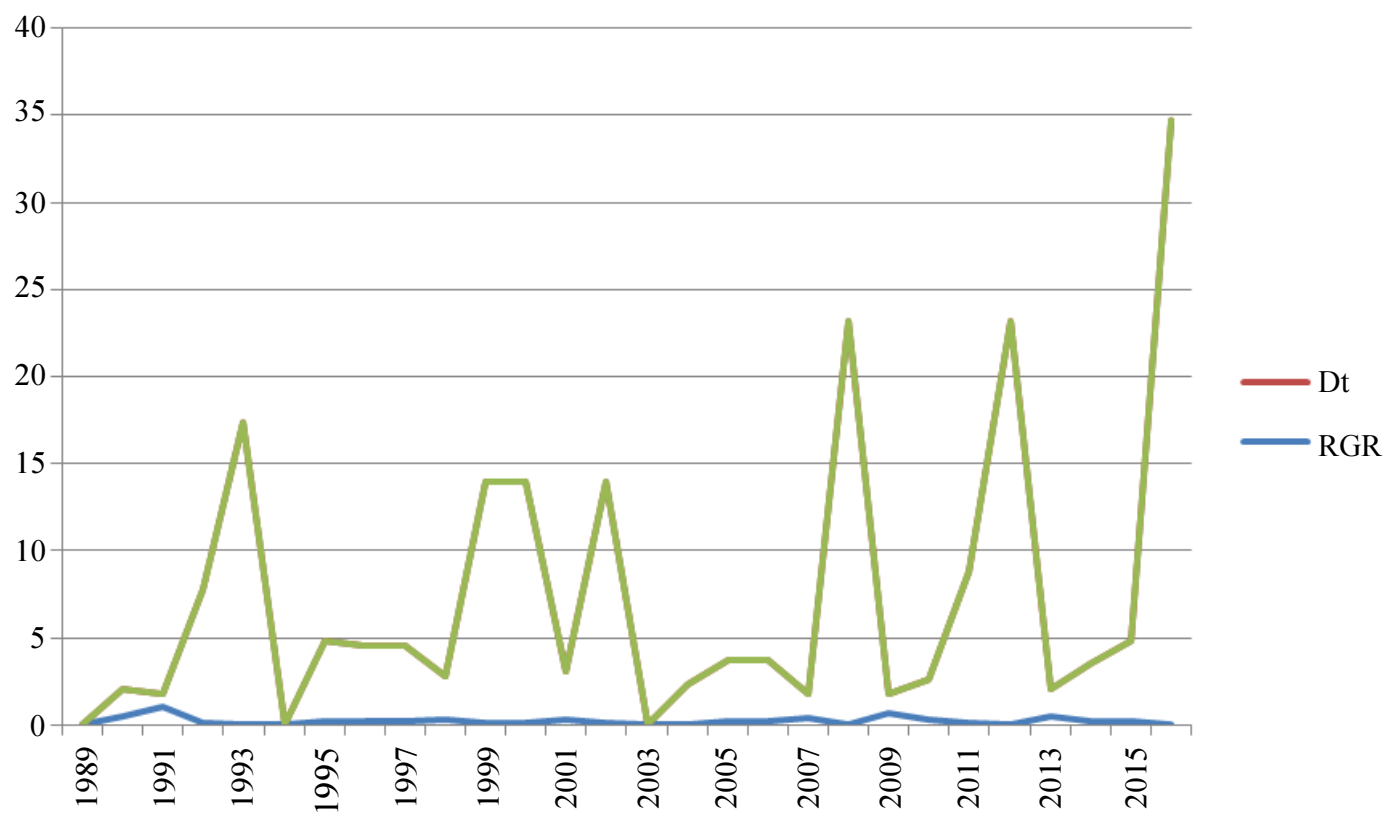

Fig. 2: Relative Growth Rate (RGR) and Doubling time (Dt) of the Publications (WOS) 


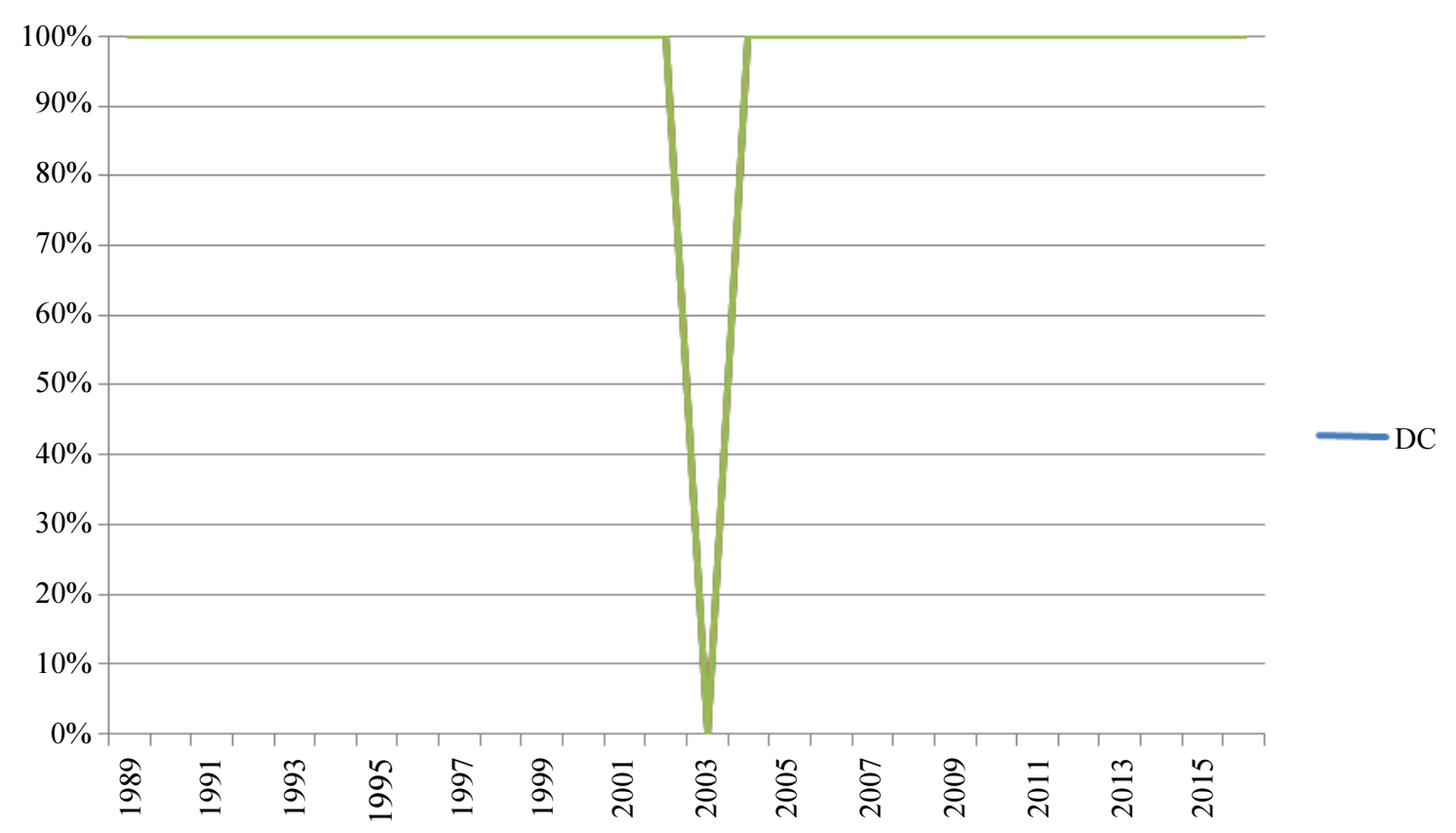

Fig. 3: Degree of collaboration of authors

Table 2: Relative Growth Rate (RGR) and Doubling time (Dt) of the publications (WOS)

\begin{tabular}{|c|c|c|c|c|c|c|}
\hline Year & No. of output & $\%$ & W1 & W2 & $\mathrm{R}(\mathrm{A})=\mathrm{W} 2-\mathrm{W} 1 / \mathrm{T} 2-\mathrm{T} 1$ & Dt. $=0.693 / \mathrm{R}(\mathrm{A})$ \\
\hline 1989 & 11 & 0.26 & 0.00 & 2.39 & 0.00 & 0.00 \\
\hline 1990 & 17 & 0.40 & 2.39 & 2.83 & 0.44 & 1.57 \\
\hline 1991 & 47 & 1.13 & 2.83 & 3.85 & 1.02 & 0.69 \\
\hline 1992 & 43 & 1.02 & 3.85 & 3.76 & 0.09 & 7.70 \\
\hline 1993 & 45 & 1.08 & 3.76 & 3.80 & 0.04 & 17.32 \\
\hline 1994 & 45 & 1.08 & 3.80 & 3.80 & 0.00 & 0.00 \\
\hline 1995 & 52 & 1.25 & 3.80 & 3.95 & 0.15 & 4.62 \\
\hline 1996 & 61 & 1.45 & 3.95 & 4.11 & 0.16 & 4.33 \\
\hline 1997 & 52 & 1.25 & 4.11 & 3.95 & 0.16 & 4.33 \\
\hline 1998 & 69 & 1.66 & 3.95 & 4.23 & 0.28 & 2.47 \\
\hline 1999 & 66 & 1.58 & 4.23 & 4.18 & 0.05 & 13.86 \\
\hline 2000 & 69 & 1.66 & 4.18 & 4.23 & 0.05 & 13.86 \\
\hline 2001 & 89 & 2.14 & 4.23 & 4.48 & 0.25 & 2.77 \\
\hline 2002 & 84 & 2.02 & 4.48 & 4.43 & 0.05 & 13.86 \\
\hline 2003 & 0 & 0.00 & 0.00 & 0.00 & 0.00 & 0.00 \\
\hline 2004 & 82 & 1.97 & 4.43 & 4.40 & 0.03 & 2.31 \\
\hline 2005 & 100 & 2.40 & 4.40 & 4.60 & 0.20 & 3.46 \\
\hline 2006 & 101 & 2.42 & 4.60 & 4.61 & 0.20 & 3.46 \\
\hline 2007 & 143 & 3.44 & 4.61 & 4.96 & 0.35 & 1.38 \\
\hline 2008 & 148 & 3.56 & 4.96 & 4.99 & 0.03 & 23.10 \\
\hline 2009 & 277 & 6.67 & 4.99 & 5.62 & 0.63 & 1.10 \\
\hline 2010 & 308 & 7.41 & 5.62 & 5.73 & 0.31 & 2.23 \\
\hline 2011 & 287 & 6.91 & 5.73 & 5.65 & 0.08 & 8.66 \\
\hline 2012 & 294 & 7.08 & 5.65 & 5.68 & 0.03 & 23.10 \\
\hline 2013 & 447 & 10.76 & 5.68 & 6.10 & 0.42 & 1.65 \\
\hline 2014 & 365 & 8.79 & 6.10 & 5.89 & 0.21 & 3.30 \\
\hline 2015 & 420 & 10.11 & 5.89 & 6.04 & 0.15 & 4.63 \\
\hline 2016 & 430 & 10.35 & 6.04 & 6.06 & 0.02 & 34.65 \\
\hline Total & 4152 & 100.00 & 118.24 & 124.32 & 5.40 & 200.41 \\
\hline
\end{tabular}


C. Baskaran and P. Ramesh Babu / Journal of Social Sciences 2019, Volume 15: 17.28 DOI: $10.3844 /$ jssp.2019.man.m.n

Table 3: Degree of collaboration of authors

\begin{tabular}{lcccc}
\hline Year & Single authored & $\begin{array}{l}\text { Multi authored } \\
(\mathrm{Nm})\end{array}$ & $\begin{array}{l}\text { Total No. of } \\
\text { authored (NS + Nm) }\end{array}$ & $\begin{array}{c}\text { Degree of } \\
\text { collaboration }\end{array}$ \\
\hline 1989 & 1 & 10 & 11 & 0.90 \\
1990 & 2 & 15 & 17 & 0.88 \\
1991 & 6 & 41 & 47 & 0.87 \\
1992 & 5 & 38 & 43 & 0.88 \\
1993 & 6 & 39 & 45 & 0.86 \\
1994 & 11 & 34 & 45 & 0.75 \\
1995 & 12 & 40 & 62 & 0.64 \\
1996 & 9 & 52 & 61 & 0.85 \\
1997 & 10 & 42 & 52 & 0.80 \\
1998 & 9 & 60 & 69 & 0.86 \\
1999 & 6 & 60 & 66 & 0.90 \\
2000 & 20 & 49 & 69 & 0.71 \\
2001 & 16 & 73 & 89 & 0.82 \\
2002 & 20 & 64 & 84 & 0.76 \\
2003 & 0 & 0 & 0 & 0.00 \\
2004 & 19 & 63 & 82 & 0.76 \\
2005 & 18 & 82 & 100 & 0.82 \\
2006 & 23 & 78 & 101 & 0.77 \\
2007 & 18 & 125 & 143 & 0.87 \\
2008 & 11 & 137 & 148 & 0.92 \\
2009 & 18 & 259 & 277 & 0.93 \\
2010 & 15 & 283 & 298 & 0.94 \\
2011 & 16 & 271 & 287 & 0.94 \\
2012 & 20 & 274 & 294 & 0.93 \\
2013 & 35 & 412 & 447 & 0.92 \\
2014 & 21 & 344 & 365 & 0.94 \\
2015 & 26 & 394 & 420 & 0.93 \\
2016 & 29 & 401 & 430 & \\
Total & 402 & 3750 & 4152 & \\
\hline & & & & \\
\end{tabular}

Table 4: Collaborative Index (CI)

\begin{tabular}{lcccc}
\hline Year & Single authored & Multi authored & Total no. of authored & CI \\
\hline 1989 & 1 & 10 & 11 & 0.08 \\
1990 & 2 & 15 & 17 & 1.06 \\
1991 & 6 & 41 & 47 & 0.01 \\
1992 & 5 & 38 & 43 & 1.05 \\
1993 & 6 & 39 & 45 & 1.05 \\
1994 & 11 & 34 & 45 & 0.02 \\
1995 & 12 & 40 & 62 & 0.02 \\
1996 & 9 & 52 & 61 & 1.38 \\
1997 & 10 & 42 & 52 & 1.90 \\
1998 & 9 & 60 & 69 & 0.01 \\
1999 & 6 & 60 & 66 & 0.08 \\
2000 & 20 & 49 & 69 & 0.03 \\
2001 & 16 & 73 & 89 & 1.75 \\
2002 & 20 & 64 & 84 & 2.50 \\
2003 & 0 & 0 & 0 & 0.00 \\
2004 & 19 & 63 & 82 & 2.41 \\
2005 & 18 & 82 & 100 & 1.15 \\
2006 & 23 & 78 & 101 & 2.36 \\
2007 & 18 & 125 & 143 & 1.15 \\
2008 & 11 & 137 & 148 & 0.06 \\
2009 & 18 & 259 & 277 & 5.56 \\
2010 & 15 & 283 & 298 & 4.24 \\
2011 & 16 & 271 & 287 & 0.04 \\
2012 & 20 & 274 & 294 & 0.05 \\
2013 & 35 & 412 & 447 & 0.06 \\
2014 & 21 & 344 & 365 & 0.04 \\
2015 & 26 & 394 & 420 & 0.05 \\
2016 & 29 & 401 & 430 & 29.09 \\
Total & 402 & 3750 & 4152 & \\
\hline & & & & \\
\hline
\end{tabular}




\section{Collaborative Index (CI)}

Table 4 shows total number of single and multiple authored publications were contributed 373 and 3349 respectively during the period of study. It witnessed that CI values measured between 0.04 and 5.56 in the year 2014 and 2009 respectively.

It could be analyzed collaborative Index range between 0.01 and 5.56 calculated in the year 1998 and 2009 respectively and the whole CI growth was a fluctuated during the study period (Fig. 4).

\section{Collaborative Co-efficient (CC)}

It has been analyzed that the Collaborative Co-efficient of the authors in Forensic Medicine. Table 5 examines that CI growth was witnessed an increased and a decreased trend overall study period. The $\mathrm{CC}$ values measured between 9.87 in 2016 and 6.15 in 1995 and 1995, the whole CC observed as 230.26 over period of study (Fig. 5).

\section{Modified Collaborative Co-efficient (MCC)}

The equation is not defined for the trivial case when $\mathrm{A}=1$, which is not a problem since collaboration is meaningless unless at least two authors are available. CC approaches MCC only when A but is otherwise strictly less than MCC by the factor 1A1:

Table 5: Collaborative Co-efficient (CC)

\begin{tabular}{lrrrr}
\hline Year & Single authored & Multi authored & Total no. of authored & CC \\
\hline 1989 & 1 & 10 & 11 & 9.09 \\
1990 & 2 & 15 & 17 & 8.82 \\
1991 & 6 & 41 & 47 & 8.72 \\
1992 & 5 & 38 & 43 & 8.83 \\
1993 & 6 & 39 & 45 & 8.61 \\
1994 & 11 & 34 & 45 & 7.52 \\
1995 & 12 & 40 & 62 & 6.45 \\
1996 & 9 & 52 & 61 & 6.45 \\
1997 & 10 & 42 & 52 & 8.02 \\
1998 & 9 & 60 & 69 & 8.61 \\
1999 & 6 & 60 & 66 & 9.01 \\
2000 & 20 & 49 & 69 & 7.12 \\
2001 & 16 & 73 & 89 & 8.26 \\
2002 & 20 & 64 & 84 & 7.60 \\
2003 & 0 & 0 & 0 & 0.00 \\
2004 & 19 & 63 & 82 & 7.65 \\
2005 & 18 & 82 & 100 & 8.29 \\
2006 & 23 & 78 & 101 & 7.78 \\
2007 & 18 & 125 & 143 & 8.72 \\
2008 & 11 & 137 & 148 & 9.21 \\
2009 & 18 & 259 & 277 & 9.33 \\
2010 & 15 & 283 & 298 & 9.42 \\
2011 & 16 & 271 & 287 & 9.47 \\
2012 & 20 & 274 & 294 & 9.33 \\
2013 & 35 & 412 & 447 & 9.26 \\
2014 & 21 & 344 & 365 & 9.45 \\
2015 & 26 & 394 & 420 & 9.37 \\
2016 & 29 & 401 & 430 & 230.26 \\
Total & 402 & 3750 & 452 & \\
\hline
\end{tabular}

It is analysed that Modified Collaborative Coefficient of authors contributed publications in Forensic Medicine. Table 6 examined the MCC was an increased and suddenly appeared a decreased trend during19892016. The MCC values noticed that 0.02 in 1989 and 1.94 in 2016. It could be found to be whole MCC measured as 11.16 during the study period (Fig. 6).

\section{Exponential Growth for Authors in Forensic} Medicine Research

Value $\mathrm{n}$ in the field of Forensic Medicine is being analysed, it has calculated the exponential growth is $n=$ 4.4320914 for author data presented in Table 7. It shows the calculation for exponent of the author productivity as given formulas below:

$$
\begin{aligned}
& N=N \sum x y-\sum x \sum y \\
& N \sum x^{2}-\left(\sum x\right)^{2} \\
& =22 \times 278.83-64.81 \times 131.89 \\
& 22 \times 129.62-64.81 \times 64.81 \\
& =800499.76 / 180614.45 \\
& =4.4320914
\end{aligned}
$$


C. Baskaran and P. Ramesh Babu / Journal of Social Sciences 2019, Volume 15: 17.28 DOI: 10.3844/jssp.2019.manam

Table 6: Modified Collaborative Co-efficient (MCC)

\begin{tabular}{lcccc}
\hline Year & Single authored & Multi authored & Total No. of authored & MCC \\
\hline 1989 & 1 & 10 & 11 & 0.02 \\
1990 & 2 & 15 & 17 & 0.04 \\
1991 & 6 & 41 & 47 & 0.12 \\
1992 & 5 & 38 & 43 & 0.11 \\
1993 & 6 & 39 & 45 & 0.12 \\
1994 & 11 & 34 & 45 & 0.12 \\
1995 & 12 & 40 & 62 & 0.16 \\
1996 & 9 & 52 & 61 & 0.16 \\
1997 & 10 & 42 & 52 & 0.13 \\
1998 & 9 & 60 & 69 & 0.13 \\
1999 & 6 & 60 & 66 & 0.17 \\
2000 & 20 & 49 & 69 & 0.18 \\
2001 & 16 & 73 & 89 & 0.23 \\
2002 & 20 & 64 & 84 & 0.22 \\
2003 & 0 & 0 & 0 & 0.00 \\
2004 & 19 & 63 & 82 & 0.22 \\
2005 & 18 & 82 & 100 & 0.26 \\
2006 & 23 & 78 & 101 & 0.27 \\
2007 & 18 & 125 & 143 & 0.38 \\
2008 & 11 & 137 & 148 & 0.39 \\
2009 & 18 & 259 & 277 & 0.74 \\
2010 & 15 & 283 & 298 & 0.80 \\
2011 & 16 & 271 & 287 & 0.77 \\
2012 & 20 & 274 & 294 & 0.78 \\
2013 & 35 & 412 & 447 & 1.20 \\
2014 & 21 & 344 & 365 & 0.98 \\
2015 & 26 & 394 & 420 & 1.12 \\
2016 & 29 & 401 & 430 & 1.16 \\
Total & 402 & 3750 & 4152 & \\
\hline & & & & \\
\hline
\end{tabular}

Table 7: Exponential growth for authors in forensic medicine research

\begin{tabular}{|c|c|c|c|c|c|}
\hline No. of articles (X) & Observed (Y) & $X=\log (X)$ & $\mathrm{Y}=\log (\mathrm{Y})$ & $\mathrm{XY}$ & $X^{2}$ \\
\hline 1 & 1345 & 0.00 & 7.20 & 0.00 & 0.00 \\
\hline 2 & 1142 & 0.69 & 7.04 & 4.85 & 1.38 \\
\hline 3 & 984 & 1.09 & 6.89 & 7.51 & 2.18 \\
\hline 4 & 902 & 1.38 & 6.80 & 9.38 & 2.76 \\
\hline 5 & 887 & 1.60 & 6.78 & 10.84 & 3.20 \\
\hline 6 & 834 & 1.79 & 6.72 & 12.04 & 3.58 \\
\hline 7 & 764 & 1.94 & 6.63 & 12.86 & 3.88 \\
\hline 8 & 712 & 2.07 & 6.56 & 13.57 & 4.14 \\
\hline 9 & 684 & 2.19 & 6.52 & 14.27 & 4.38 \\
\hline 10 & 602 & 2.30 & 6.40 & 14.72 & 4.60 \\
\hline 11 & 542 & 2.39 & 6.29 & 15.03 & 4.78 \\
\hline 12 & 424 & 2.48 & 6.04 & 14.97 & 4.96 \\
\hline 13 & 312 & 2.56 & 5.74 & 14.69 & 5.12 \\
\hline 14 & 204 & 2.63 & 5.31 & 13.96 & 5.26 \\
\hline 15 & 197 & 2.70 & 5.28 & 14.25 & 5.40 \\
\hline 16 & 168 & 2.77 & 5.12 & 14.18 & 5.54 \\
\hline 17 & 112 & 2.83 & 4.71 & 13.32 & 5.66 \\
\hline 18 & 97 & 2.89 & 4.57 & 13.20 & 5.78 \\
\hline 19 & 86 & 2.94 & 4.54 & 13.34 & 5.88 \\
\hline 20 & 52 & 2.99 & 3.95 & 11.81 & 5.98 \\
\hline 21 & 32 & 3.04 & 3.46 & 10.51 & 6.08 \\
\hline 22 & 18 & 3.09 & 2.89 & 8.93 & 6.18 \\
\hline 23 & 12 & 3.13 & 2.48 & 7.76 & 6.26 \\
\hline 24 & 9 & 3.17 & 2.19 & 6.94 & 6.34 \\
\hline 25 & 3 & 3.21 & 1.09 & 3.49 & 6.42 \\
\hline 31 & 2 & 3.48 & 0.693 & 2.41 & 6.96 \\
\hline 32 & 1 & 3.46 & 0.00 & 0.00 & 6.92 \\
\hline Total & & 64.81 & 131.89 & 278.83 & 129.62 \\
\hline
\end{tabular}




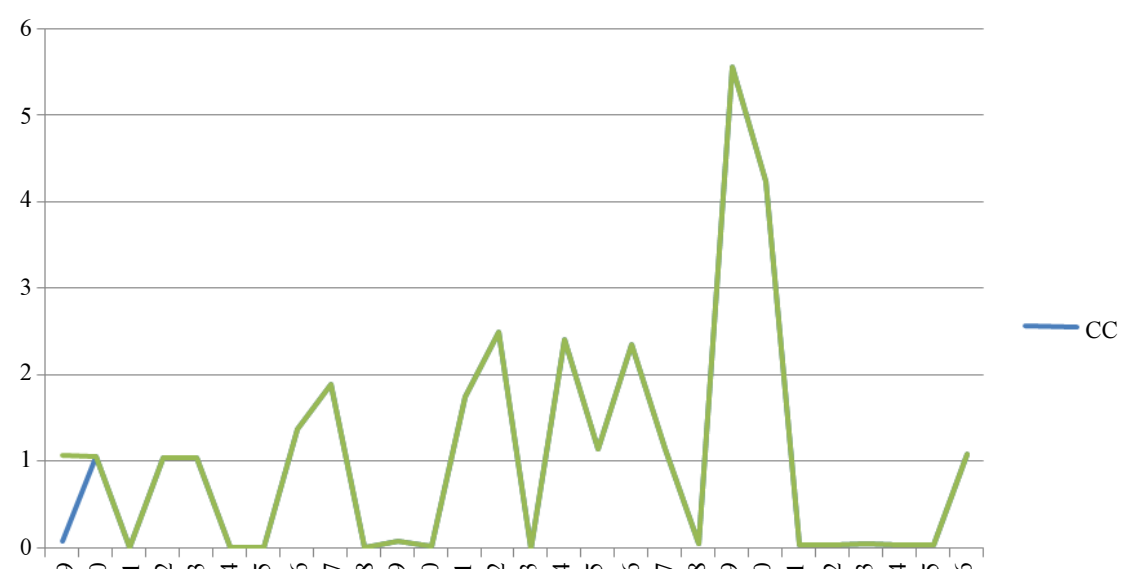

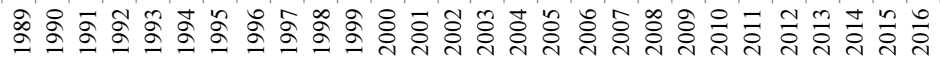

Fig. 4: Collaborative Index (CI)

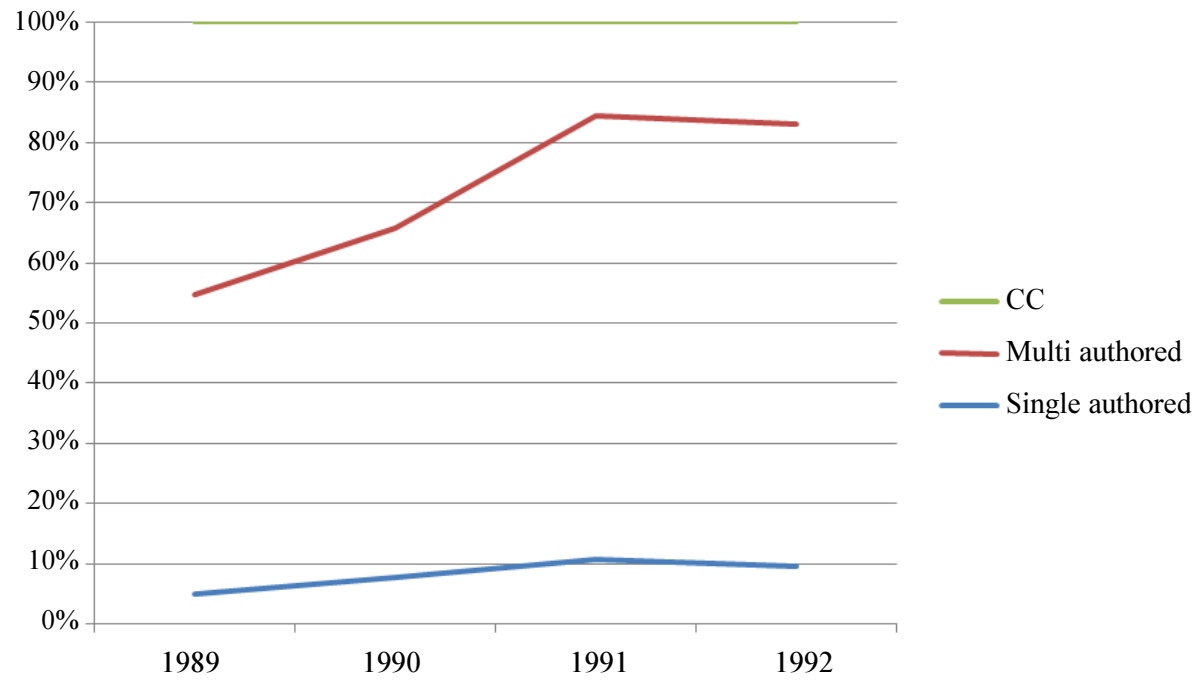

Fig. 5: Collaborative Co-efficient (CC)

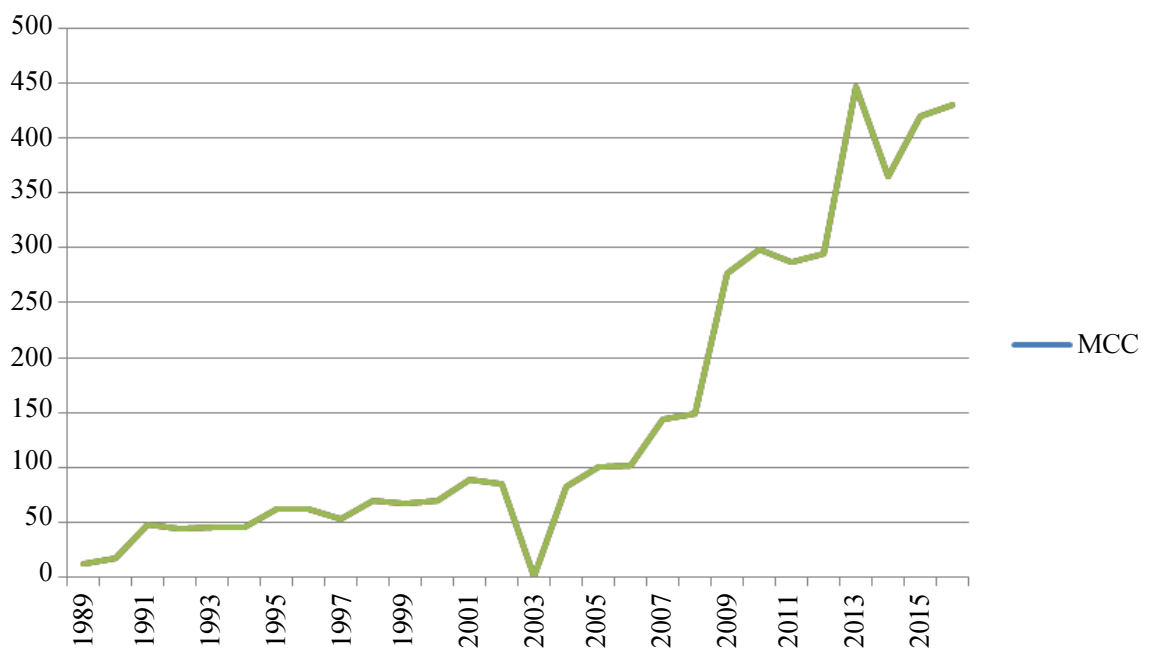

Fig. 6: Modified Collaborative Co-efficient (MCC) 


\section{Year-Wise Activity Index of Forensic Medicine} Research

It has been analysed that growth of B was found to be an increasing and a decreasing trend perform in the whole study period. Table 8 shows the whole Activity Index (A) was measured from Indian Output 0.84 by throughout study period. It can be found that activity index of world output in Forensic Medicine (B) was an increasing and a decreasing trend in whole study period. It is indicated the year-wise analysis of Activity Index (AI) was higher than an average $(\mathrm{A} 1>1$ on the over period over 28 years (1989-2016).

It could be discussed that Activity Index Vs. yearwise analysis of Indian output and World output in Forensic Medicine. It witnessed that whole Activity Index found between 1 and 11 , further, the activity trend appear to be a fluctuated trend during 1989-2016.

\section{Major Findings}

- Largest output was found 447 publications in the year 2013 , it followed by $420(10.38 \%)$ of the publication identified in the year 2015. There were no record published in the year 2003
- RGR was a fluctuates trend between 0.02 and 1.02 in 2005, 2006 and 1991 respectively. Dt was analyzed between 1.1 and 34.65 in the year 2009 and 2016 respectively during the study period

- DC between 0.64 and 0.94 and overall DC measured to be 23.08 throughout study period. The study could be found DC was an increased and a decreased trend appeared in whole study period

- Collaborative Index between 0.01 and 5.56 appeared in 1998 and 2009 respectively. It is witnessed that whole growth of CI was a fluctuated trend during the study period

- CC values measured between 9.87 in 2016 and 6.15 in 1995 and 1995, the whole CC observed as 230.26 during the period of study

- The MCC values noticed that 0.02 in 1989 and 1.94 in 2016 and the whole MCC measured as 11.16 during period of study

- Activity Index Vs. year-wise analysis of Indian output and World output in Forensic Medicine. It witnessed that whole Activity Index found between 1 and 11 , further, the activity trend appear to be a fluctuated trend during 1989-2016

- The exponential growth was calculated $\mathrm{n}=$ 4.4320914 for author

Table 8: Year- wise activity index of forensic medicine research

\begin{tabular}{|c|c|c|c|c|c|c|}
\hline Year & Indian output & $(\mathrm{A})$ & World output & (B) & $\mathrm{A} / \mathrm{B}$ & $\mathrm{AI}$ \\
\hline 1989 & 4 & 0.01 & 11 & 0.29 & 0.030 & 11 \\
\hline 1990 & 5 & 0.01 & 17 & 0.45 & 0.020 & 7 \\
\hline 1991 & 8 & 0.02 & 47 & 1.25 & 0.010 & 4 \\
\hline 1992 & 7 & 0.02 & 43 & 1.15 & 0.010 & 4 \\
\hline 1993 & 9 & 0.03 & 45 & 1.20 & 0.020 & 7 \\
\hline 1994 & 6 & 0.02 & 45 & 1.20 & 0.010 & 4 \\
\hline 1995 & 9 & 0.03 & 52 & 1.39 & 0.020 & 7 \\
\hline 1996 & 8 & 0.02 & 61 & 1.69 & 0.010 & 4 \\
\hline 1997 & 9 & 0.03 & 52 & 1.2 & 0.020 & 7 \\
\hline 1998 & 8 & 0.02 & 69 & 1.85 & 0.010 & 4 \\
\hline 1999 & 9 & 0.03 & 66 & 1.77 & 0.010 & 4 \\
\hline 2000 & 9 & 0.03 & 69 & 1.85 & 0.010 & 4 \\
\hline 2001 & 7 & 0.02 & 89 & 2.39 & 0.008 & 3 \\
\hline 2002 & 7 & 0.02 & 84 & 2.35 & 0.008 & 3 \\
\hline 2003 & 0 & 0.00 & 0 & 0.00 & 0.000 & 0 \\
\hline 2004 & 9 & 0.03 & 82 & 2.20 & 0.010 & 4 \\
\hline 2005 & 8 & 0.02 & 100 & 2.68 & 0.007 & 3 \\
\hline 2006 & 10 & 0.03 & 101 & 2.71 & 0.010 & 4 \\
\hline 2007 & 13 & 0.04 & 143 & 3.84 & 0.010 & 4 \\
\hline 2008 & 11 & 0.04 & 148 & 3.95 & 0.010 & 4 \\
\hline 2009 & 13 & 0.04 & 277 & 7.44 & 0.005 & 2 \\
\hline 2010 & 12 & 0.04 & 308 & 8.27 & 0.004 & 1 \\
\hline 2011 & 17 & 0.06 & 287 & 7.71 & 0.007 & 3 \\
\hline 2012 & 11 & 0.04 & 294 & 8.89 & 0.004 & 1 \\
\hline 2013 & 13 & 0.04 & 447 & 12.00 & 0.003 & 1 \\
\hline 2014 & 15 & 0.05 & 365 & 9.80 & 0.005 & 2 \\
\hline 2015 & 16 & 0.05 & 420 & 11.28 & 0.004 & 1 \\
\hline 2016 & 15 & 0.05 & 430 & 12.16 & 0.004 & 1 \\
\hline Total & 268 & 0.84 & 4152 & 12.96 & 0.279 & 103 \\
\hline
\end{tabular}




\section{Conclusion}

The study analysed the publication pattern into activity Index and exponential growth of authors in Forensic Medicine during 1989-2016. The highest Dt was observed at 13.86 in 2002. It also seems the lowest Dt found to be 0.32 in the year of 2015. It could find overall RGR was 9.12 and Dt was 172.42 in the whole study period. The study discussed on the publications trend in terms of author Collaborations and productivity, Source-wise publications, Institutionswise productivity, citations counting and h-index etc. measured in the field of Forensic Medicine during 1989-2016. The aim of the study deals the medico legal autopsy brings still more medical advantages and benefits. MCC were noticed that 0.02 in 1989 and 1.94 in 2016. It also happened to be the whole MCC measured as 11.16 during the period of study.

The study finds that there was witnessed that whole Activity Index could be found between 1 and 11, also activity trend is appear a fluctuated trend during 19892016. The aim of the study deals the medico legal autopsy brings still more medical advantages and benefits. The ones presented here are not imaginary, hypothetical, or unrealistic pros of this activity, but true and palpable outcomes of the author's daily medico legal work on necropsies. Quality and training, that is, education, is indeed one of the three major platforms on which forensic pathology needs to build in the future, the other two aims being good legislation and organization. It is impossible to be a credible and convincing teacher unless one has continuing practical experience on the subject. The scholarly outcomes of the research collaboration of Forensic Medicine at global context there should be constant support and encouragement from the Government and WHO to bring out qualitative research in the field. In this study, the research part has been divided that in first part as Year- wise output of Forensic Medicine from Web of Science (WOS) and PubMed database.

\section{Author's Contributions}

Dr. C. Baskaran: Librarian (Professor Cardre), Research Supervisor in Library and Information Science \& Project Director (ICSSR), Alagappa University, Karaikudi, India, He published more than 100 research papers and 3 books. He has been acted experts in various commitees. Six Ph.D awarded and Eight Ph.D undergoing under his research supervision.

P. Ramesh Babu: Research Scholar in the Department of Library and Information Science, He has more than 15 years of experience in Library/Digital Archives areas.

\section{Ethics}

This article is original and contains unpublished materail. The corresponding author confirm that all of other author have read and approved the manuscript and there are no ethical issues involved.

\section{References}

Baskaran, C., 2015. Research productivity of enzymes literature: A Scientometric study. Int. J. Library Sci. Inform. Manage., 1: 17-25.

Baskaran, C., 2016. A scientometric study on bioinformatics literature during 1999-2013. Int. J. Library Sci. Inform. Manage., 2: 62-71.

de Granda-Orive, J.I., F.G. Río, R.A. Benavent, J.C.V. Zurían and C.A.J. Ruiz et al., 2007. Spanish productivity in smoking research relative to world and European union productivity from 1999 through 2003, analyzed with the science citation index. Arch Bronconeumol., 43: 212-218.

DOI: $10.1016 /$ S1579-2129(07)60053-6

de Granda-Orive, J.I., S. Villanueva-Serrano, R. Aleixandre-Benavent, J.C. Valderrama-Zurián and A. Alonso-Arroyo et al., 2009. [Network of international scientific collaboration on smoking: Analysis of coauthorship through the science citation index (1999-2003).]. Gac Sanit., 23: 222.e34-43. DOI: 10.1016/j.gaceta.2008.05.002

de Solla Price, D., 1977. Science, Technology and Society: A Cross-Disciplinary Perspective. 1st Edn., SAGE Publications, pp: 607.

Garfield, E., 2007. From The Science of Science to Scientometrics. Visualizing the History of Science with Histcite software. Proceedings of the 11th International Conference of the International Society for Scientometrics and Informetrics, (SSI' 07), ISSI, Madrid, Spain.

Jeyasekar, J.J. and P. Saravanan, 2013. Journal of forensic sciences: A bibliometric study for the period 2006 to 2010. Proceedings of the 2nd National Conference on Scientometrics and Knowledge Management, (SKM' 13), Dharwad, India.

Kaye, S., 1992. The rebirth and blooming of forensic medicine, Milton Helpern Lecture. J. Forensic Med. Pathol., 13: 299-304. PMID: 1288258

Kovacevic, S., 1989. Forensic medicine in Yugoslavia. J. Forensic Med. Pathol., 10: 172-173. PMID: 2662753

Kolle, S.R. and T.H. Shankarappa, 2016. Scientometric analysis of scientific papers from India (1989-2015) based on WoS data. SRELS J. Inform. Manage., 53: 250-256. DOI: 10.17821/srels/2016/v53i6/90091

Palanivel, K. and C. Baskaran, 2018. Bibliometric analysis of the journal-economic affairs. Int. J. Res. Library Sci., 4: 7-15. 
Radhakrishnan, S. and C. Baskaran, 2018. Journal of solar energy engineering, transactions of the ASME: A scientometric analysis. J. Adv. Library Inform. Sci., 7: 103-108.

Ramesh Babu, P. and C. Baskaran, 2017. Research pattern on forensic medicine in global output: A scientometric analysis. Int. J. Library Sci. Inform. Manage., 3: 53-64.

Saukko, P. and B. Knight, 2004. Knight's Forensic Pathology. 3rd Edn., CRC Press, London, ISBN-10: 1444115383, pp: 720.

Sevinc, A., 2004. Web of science: A unique method of cited reference searching. J. Natl. Med. Assoc., 96: 980-983. PMID: 15253331

Sevinc, A., 2005. Multilingual approach to "Web of Science', J. Natl. Med. Assoc., 97: 116-117. PMID: 15719884
Sivakami, N. and C. Baskaran, 2016. Time series analysis of swine flu literature during 1991-2013. Int. J. Library Sci. Inform. Manage., 2: 38-46.

Smith, D.R., 2007. Historical development of the journal impact factor and its relevance for occupational health. Ind. Health, 45: 730-742. PMID: 18212467

Subramanyam, N. and M. Krishnamurthy, 2017. IndMed: An evaluative study on the coverage of Indian medical literature. SRELS J. Inform. Manage. DOI: 10.17821/srels/2017/v54i1/101184

Vitzthum, K., C. Scutaru, L. Musial-Bright, D. Quarcoo and T. Welte et al., 2010. Scientometric analysis and combined density-equalizing mapping of Environmental Tobacco Smoke (ETS) research. PLoS ONE, 5: 1-10. DOI: 10.1371/journal.pone.0011254 